\title{
Vascular endothelial growth inhibitor 174 and its functional domains inhibit epithelial-mesenchymal transition in renal cell carcinoma cells in vitro
}

\author{
NING ZHANG ${ }^{1 *}$, BAOAN HONG $^{2 *}$, WENYONG LIAN ${ }^{3}$, CHANGHUA ZHOU $^{4}$, SIQI CHEN $^{4}$, \\ XIN DU ${ }^{5}$, XIAOHU DENG ${ }^{6}$, SHAYIREMU DUOERKUN ${ }^{7}$, QING $\mathrm{LI}^{4}$, YONG YANG ${ }^{1}$ and $\mathrm{KAN} \mathrm{GONG}^{2}$ \\ ${ }^{1}$ Department of Urology, Peking University Cancer Hospital, Beijing Institute for Cancer Research, Beijing 100142; \\ ${ }^{2}$ Department of Urology, Peking University First Hospital, Beijing 100034; ${ }^{3}$ Department of Urology, \\ Xinjiang Production and Construction Corps First Division Hospital, Aksu, Xinjiang 843000; \\ ${ }^{4}$ School of Pharmaceutical Sciences, Center for Cellular and Structural Biology, Sun Yat-Sen University, \\ Guangzhou, Guangdong 510006; ${ }^{5}$ Department of Urology, Beijing Chaoyang Hospital, Capital Medical University, \\ Beijing 100020; ${ }^{6}$ Department of Urology, Karamay People's Hospital, Karamay, Xinjiang 834000; \\ ${ }^{7}$ Department of Urology, Hami District Central Hospital, Hami, Xinjiang 839000, P.R. China
}

Received August 3, 2016; Accepted June 8, 2017

DOI: $10.3892 / \mathrm{ijmm} .2017 .3033$

\begin{abstract}
The present study was carried out to investigate the effects of vascular endothelial growth inhibitor 174 (VEGI174) and its functional domains (V7 and V8) on epithelial-mesenchymal transition (EMT) in renal cell carcinoma (RCC) cells in vitro. The RCC cell lines A498 and 786-O were used in this study. Based on our preliminary study, we selected full-length VEGI174 and its functional domains (V7 and V8) as the target genes in this study. Plasmids containing VEGI174, V7 or V8 transgenes were constructed and transfected into A498 and 786-O cell lines. Cytological activity was tested during cell culture. Quantitative PCR and western blot analysis were performed to determine the expression levels of EMT markers (E-cadherin, vimentin, $\beta$-catenin and Slug). Overexpression of VEGI174, V7 or V8 did not have a significant influence on cell viability $(\mathrm{P}>0.05)$. The mRNA level of E-cadherin was significantly upregulated, while that of vimentin was downregulated in $\mathrm{A} 498^{\text {VEGIexp }}$, $4498^{\mathrm{V} 7 \exp }$, $\mathrm{A} 498^{\mathrm{V} 8 \exp }, 786-\mathrm{O}^{\text {VEGIexp }}$, $786-\mathrm{O}^{\mathrm{V} 7 \exp }$ and $786-\mathrm{O}^{\mathrm{V} 8 \exp }$ cells compared with the cells
\end{abstract}

Correspondence to: Dr Ning Zhang, Department of Urology, Peking University Cancer Hospital, Beijing Institute for Cancer Research, 52 Fucheng Road, Haidian, Beijing 100142, P.R. China E-mail: niru7429@126.com

Dr Kan Gong, Department of Urology, Peking University First Hospital, 8 Xishiku Street, Xicheng, Beijing 100034, P.R. China

E-mail: gongkan2004@yahoo.com.cn

*Contributed equally

Key words: renal cell carcinoma, vascular endothelial growth inhibitor, epithelial-mesenchymal transition, E-cadherin, vimentin, $\beta$-catenin, Slug containing the empty plasmid controls $(\mathrm{P}<0.05)$. The western blot results showed that changes in protein expression levels were consistent with the changes in mRNA expression. Both the mRNA and protein expression levels of $\beta$-catenin and Slug were downregulated in the A498 ${ }^{\text {VEGIexp }}$, A $498^{\mathrm{V} 7 \mathrm{exp}}$, A498 ${ }^{\mathrm{V} 8 \mathrm{exp}}$,

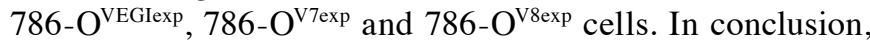
overexpression of VEGI174, V7 or V8 inhibited EMT in A498 and 786-O cells. Notably, V7 and V8 are two effective functional domains of VEGI174 that have the potential to be studied for peptide synthesis and the treatment of RCC.

\section{Introduction}

Renal cell carcinoma (RCC) accounts for approximately $4 \%$ of all adult malignancies. In 2016, 63,000 new cases of kidney cancer were estimated to be diagnosed, and more than 14,000 deaths occurred in the United States (1). Each year, more than 250,000 new cases of kidney cancer are diagnosed worldwide. In particular, metastatic RCC has a poor prognosis that seriously affects the quality of life of patients. The median overall survival of metastatic RCC is $\sim 12$ months, and the 5-year survival rate is $<10 \%$ (2). Multiple antagonists of the vascular endothelial growth factor (VEGF) signalling pathway, such as sorafenib, sunitinib, axitinib and pazopanib, have been approved for the treatment of patients with advanced RCC (3-5). While these anti-VEGF strategies have shown clinical benefits, many patients are either resistant to such therapy or, more commonly, acquire resistance to these drugs within a year of treatment initiation. Therefore, targeting additional angiogenic signalling pathways may represent a promising therapeutic approach for patients with advanced RCC.

Vascular endothelial growth inhibitor (VEGI) is a member of the tumour necrosis factor superfamily, whose members have been identified as anti-angiogenic cytokines $(6,7)$. The VEGI gene is located on human chromosome 9q32. The 
full-length VEGI gene is $\sim 17 \mathrm{~kb}$, and it consists of four exons and three introns. Three alternatively spliced isoforms of VEGI, VEGI174, VEGI192 and VEGI251 have been documented, sharing 151 common C-terminal amino acids but differing in their N-terminal regions. The initially reported VEGI protein consists of 174 amino acids, which can be divided into two parts. AA residues 1-25 at the N-terminus are the intracellular and transmembrane domains, and AA residues 26-174 at the C-terminus form an extracellular domain $(8,9)$. VEGI expression has been observed in kidney, bladder, prostate, lung, breast and colon tissues (10-13). Studies examining the biological functions of VEGI revealed that it had potential inhibitory effects on tumours. For example, our previous studies showed that VEGI overexpression substantially reduced the motility and adhesion of prostate and bladder cancer cells and suppressed renal carcinoma cell growth in vivo (14-16).

In recent years, numerous studies have demonstrated that activation of epithelial-mesenchymal transition (EMT) is a key event in the tumour invasion process (17-19). EMT is a biological phenomenon that frequently occurs in tumour tissues and is associated with local invasion and distant metastases. During this process, epithelial cells undergo multiple biochemical changes that enable them to lose the epithelial-like phenotype and transform into a mesenchymal-like phenotype. The tumour cells lose cell-cell adhesion, detach from the primary tumours and disseminate through the vasculature to other organs. It has been determined that EMT plays a significant role in tumour progression and metastasis of $\operatorname{RCC}(20,21)$.

Currently, there is interest in studying the relationship between VEGI174 and EMT. The aim of the present study was to assess whether VEGI174 has an effect on EMT in RCC cells and which functional domains of VEGI174 play an important role in this process.

\section{Materials and methods}

Cell lines. In this study, the human RCC cell lines A498 and 786-O were provided by Sun Yat-Sen University Laboratory (Guangzhou, China). Cells were cultured with Dulbecco's modified Eagle's medium (DMEM) or RPMI-1640 medium supplemented with $10 \%$ fetal bovine serum (FBS) (all from HyClone, Logan, UT, USA), penicillin and streptomycin (Gibco, Grand Island, NY, USA).

Selection of the effective functional domains of VEGI174. Based on the human VEGI174 sequence (GenBank), we designed eight different segments of the genes (V1-V8) that encode VEGI174 extracellular-function domains (Fig. 1). In our preliminary studies, full-length human VEGI174 and its functional domains (V1-V8) were separately cloned into mammalian expression plasmid vectors and then transfected into HUVECs. Our results confirmed that overexpression of VEGI174 or domains V1 through V8 was able to inhibit the motility and adhesion of HUVECs to varying degrees. In particular, the inhibitory effects produced by overexpression of V7 and V8 were more significant than those produced by overexpression of domains V1 to V6. Therefore, we selected the full-length VEGI174 and domains V7 and V8 as the target genes in this study.
Construction of VEGI174-, V7- and V8-expressing transgenes. The coding sequences for full-length VEGI174 and for its functional domains V7 and V8 were cloned into mammalian expression plasmid vectors ( $\mathrm{pEF} / \mathrm{His}$ TOPO TA; Invitrogen, Inc., Paisley, UK). The recombinant plasmid vectors were transformed into chemically competent TOP10 E. coli (Invitrogen). After verification and amplification, plasmids containing VEGI174, V7 or V8 transgenes or empty control plasmids were then transfected into A498 and 786-O cells using electroporation (Easyjet; EquiBio Ltd., Kent, UK). The transfectants were selected with blasticidin and then applied in experiments (plasmid expression groups: A498 VEGIexp, A498 ${ }^{\text {V7exp }}, \mathrm{A} 498^{\text {V8exp }}, 786-\mathrm{O}^{\text {VEGIexp }}, 786-\mathrm{O}^{\text {V7exp }}, 786-\mathrm{O}^{\text {V8exp }}$; empty control plasmid groups: $\mathrm{A} 498^{\mathrm{pEF} / \mathrm{His}}, 786-\mathrm{O}^{\mathrm{pEF} / \mathrm{His}}$ cells). Detailed experimental methods can be found in our previous studies (14-16). Full primer sequences used in this study are provided in Table I.

Cell growth assay. A total of 5,000 cells were seeded into each well of a 96-well plate and cultured in a humidified incubator at $37^{\circ} \mathrm{C}$ and $5 \% \mathrm{CO}_{2}$. During cell culture, cyto-activity was tested with a Cell Counting kit-8 (Dojindo, Kumamoto, Japan) at 24,48 and $72 \mathrm{~h}$.

Quantitative polymerase chain reaction ( $q P C R$ ). After the transfectants were cultured for $36 \mathrm{~h}$, RNA was extracted using total RNA isolation reagent (ABgene, Epsom, UK). The first cDNA strand was synthesised with HiScript II reverse transcriptase (Vanzyme, Nanjing, China). qPCR was performed using an iCycler iQ5 system (Bio-Rad, Hemel Hemstead, UK) to determine the expression level of EMT-related markers (E-cadherin, vimentin, $\beta$-catenin and Slug) in the RCC cell lines. Glyceraldehyde 3-phosphate dehydrogenase (GAPDH) served as the housekeeping gene. Full primer sequences are provided in Table I.

Western blot analysis of the expression of EMT markers. Protein quantification was determined using a bicinchoninic acid colorimetric assay (Pierce BCA Protein assay kit; Thermo Fisher Scientific, Waltham, MA, USA). Proteins undergoing sodium dodecyl sulfate polyacrylamide gel electrophoresis (SDS-PAGE) were transferred to PVDF membranes (Invitrogen) by electroblotting and probed with the primary antibodies E-cadherin $(1: 1,000,5296 \mathrm{~s}$; Cell Signaling Technology, Danvers, MA, USA), vimentin $(1: 1,000$, ab187380), $\beta$-catenin $(1: 1,000$, ab32572), Slug (1:1,000, ab51772) (all from Abcam, Cambridge, MA, USA) and secondary anti-rabbit IgG, HRP-linked antibody (1:2,000, \#7074; Cell Signaling Technology). Monoclonal mouse anti-human $\alpha$-tubulin (1:1,000, \#2125; Cell Signaling Technology) was used as an internal reference. The electrophoretic bands were analysed by an enhanced chemiluminescence system (Bio-Rad) and ImageJ software (NIH, Bethesda, MD, USA).

Statistical analysis. Statistical analyses were performed with SPSS 19.0 software (IBM Corp., Armonk, NY, USA). Statistical significance was determined by ANOVA and LSD multiple comparison t-test. A value of $\mathrm{P}<0.05$ was considered to indicate a statistically significant difference. 
Table I. Primers of the relevant genes used in the present study.

\begin{tabular}{lll}
\hline Primer & \multicolumn{1}{c}{ Forward } & \multicolumn{1}{c}{ Reverse } \\
\hline VEGI (expression) & 5'-ATGAGACGCTTTTTAAGCAA-3' & 5'-CTATAGTAAGGCTCCAAAG-3' \\
V7 (expression) & 5'-ATGACCTCTGAGTGCAGTGA-3' & 5'-ATTAGCTTGTGGGGTTCTTGCAAG-3' \\
V8 (expression) & 5'-ATGGGGACCAAGTCTGTA-3' & 5'-ATTAGCTTGTCCCCTTCTTGCAAG-3' \\
E-cadherin & 5'-TGCCCAGAAAATGAAAAAGG-3' & 5'-GTGTATGTGGCAATGCGTTC-3' \\
Vimentin & 5'-GAGAACTTTGCCGTTGAAGC-3' & 5'-GCTTCCTGTAGGTGGCAATC-3' \\
$\beta$-catenin & 5'-TGGATGGGCTGCCTCCAGGTGAC-3' & 5'-ACCAGCCCACCCCTCGAGCCC-3' \\
Slug & 5'-CATGCCTGTCATACCACAAC-3' & 5'-GGTGTCAGATGGAGGAGGG-3' \\
GAPDH (reference) & 5'-AGAAGGCTGGGGCTCATTTG-3' & 5'-AGGGGCCATCCACAGTCTTC-3'
\end{tabular}

VEGI, vascular endothelial growth inhibitor; GAPDH, glyceraldehyde 3-phosphate dehydrogenase.
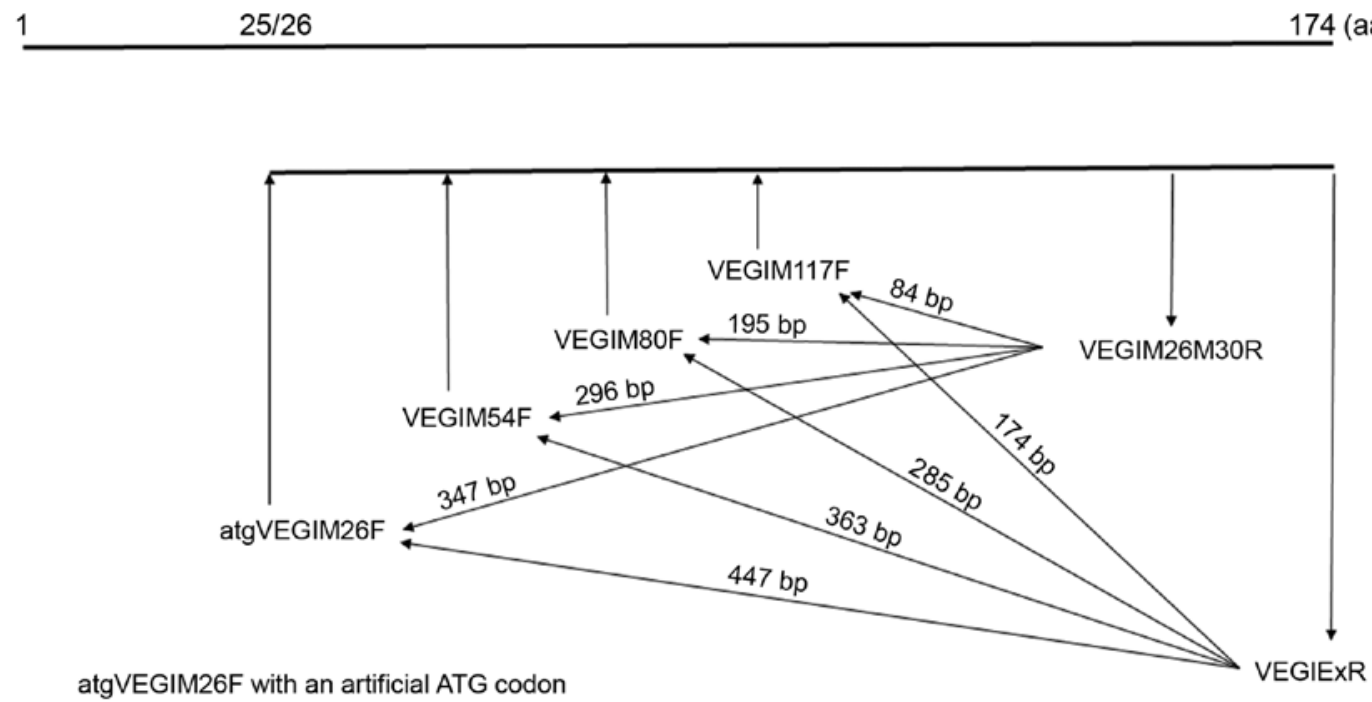

VEGIM54/80/117 with a natural ATG (met)

Figure 1. The eight designed, distinct segments of genes (V1-V8) that encode the vascular endothelial growth inhibitor 174 (VEGI174) extracellular-function domains. The V7 gene segment contains 195 bases, and the V8 segment contains 84 bases.
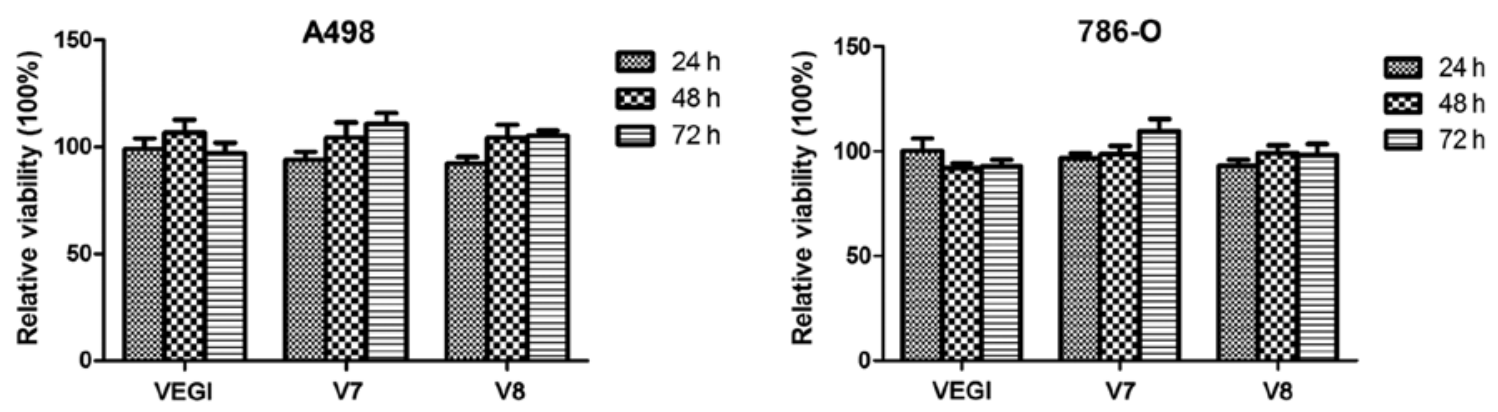

Figure 2. Relative cell viability between $\mathrm{A} 498^{\text {vEGlexp }}$, A498 ${ }^{\text {V7exp }}, \mathrm{A} 498^{\text {v8exp }}, 786-\mathrm{O}^{\text {vEGlexp }}, 786-\mathrm{O}^{\text {v7exp }}$ and 786-O $\mathrm{O}^{\text {vexp }}$ cells and empty plasmid control cells. The cell activity of the empty plasmid control group was set as the baseline. There were no significant differences $(\mathrm{P}>0.05)$.

\section{Results}

Manipulation of VEGI174, V7 and V8 overexpression has no impact on cell growth. We examined the effect of the overexpression of VEGI174, V7 and V8 on the viability of A498 and 786-O cell lines. The cell activity of the empty plasmid control group was set as the baseline. The relative cell viability between A498 VEGIexp, A498 v7exp, A498 v8exp, 786-O VEGIexp, $786-\mathrm{O}^{\mathrm{V} 7 \exp }$ and $786-\mathrm{O}^{\mathrm{V} 8 \exp }$ cells and empty plasmid control cells was not significantly different ( $\mathrm{P}>0.05)$ (Fig. 2).

The influence of VEGI174, V7 and V8 overexpression on EMT markers at the genetic level. A498 and 786-O cells were transfected with VEGI174, V7 or V8 recombinant plasmids 
A498

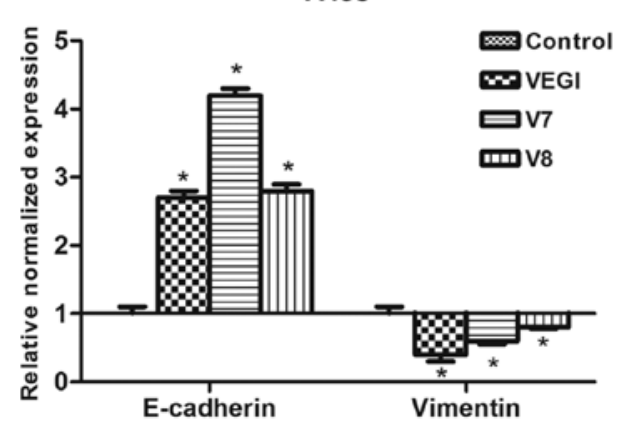

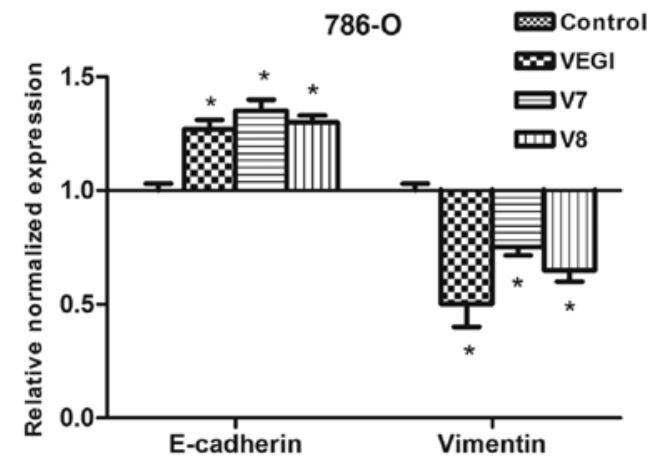

Figure 3. Verification of expression of E-cadherin and vimentin in the A498 and 786-O cells using qPCR. E-cadherin mRNA expression was markedly increased, and vimentin mRNA expression was decreased in both the A498 and 786-O cell lines that overexpressed vascular endothelial growth inhibitor 174 (VEGI174), V7 or V8 compared with the empty plasmid control cells $(\mathrm{P}<0.05)$.
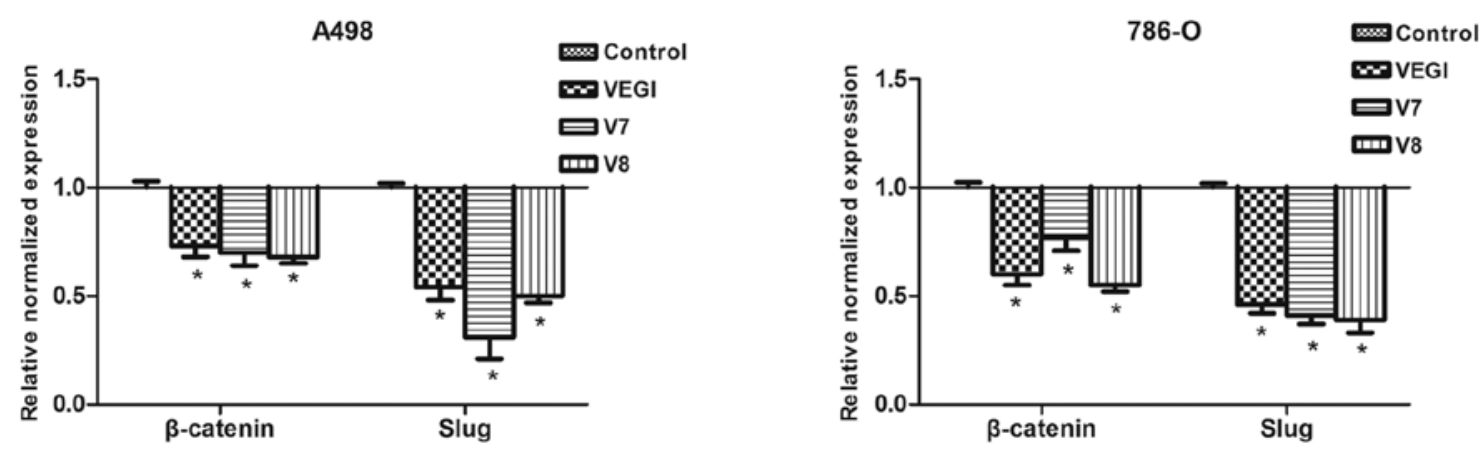

Figure 4. Verification of expression of $\beta$-catenin and Slug in the A498 and 786-O cells using qPCR. $\beta$-catenin and Slug mRNA expression was decreased in both the A498 and 786-O cell lines that overexpressed vascular endothelial growth inhibitor 174 (VEGI174), V7 or V8 compared with the empty plasmid control cells $(\mathrm{P}<0.05)$.

to create sublines expressing enhanced or suppressed levels of EMT-related markers. According to the qPCR results, mRNA expression of E-cadherin was markedly increased, while that of vimentin was decreased in the A498 ${ }^{\text {VEGIexp }}$, A $498^{\text {V7exp }}$, A $498^{\text {V8exp }}, 786-\mathrm{O}^{\text {VEGIexp }}, 786-\mathrm{O}^{\text {V7exp }}$ and $786-\mathrm{O}^{\text {V8exp }}$ cells compared with these levels in the empty plasmid controls $(\mathrm{P}<0.05)$ (Fig. 3). Furthermore, mRNA expression of E-cadherin was found to be higher in the $\mathrm{A} 498^{\mathrm{V} 7 \mathrm{exp}}$ cells than that in the $\mathrm{A} 498^{\text {VEGlexp }}$ and $\mathrm{A} 498^{\text {v8exp }}$ cells $(\mathrm{P}<0.01)$. This result indicated that the bioactivity of the V7 functional domain was higher in regard to regulating the expression of E-cadherin. $\beta$-catenin and Slug mRNA expression was downregulated in the A498 $8^{\text {VEGIexp }}, \mathrm{A} 498^{\text {V7exp }}, \mathrm{A} 498^{\text {v8exp }}, 786-\mathrm{O}^{\text {VEGIexp }}, 786-\mathrm{O}^{\text {V7exp }}$ and 786- $\mathrm{O}^{\mathrm{v8exp}}$ cells compared with the corresponding controls $(\mathrm{P}<0.05)$ (Fig. 4). However, there were no significant differences in $\beta$-catenin and Slug mRNA expression among the A498 or 786-O cells that overexpressed VEGI174, V7 or V8 ( $\mathrm{P}>0.05)$.

Effect of VEGI174, V7 and V8 overexpression on EMT markers at the protein level. Compared with the empty plasmid controls, a significant increase in E-cadherin and a decrease in vimentin were noted in the A498 ${ }^{\text {VEGlexp }}$, A498 ${ }^{\text {V7exp }}$, A498 ${ }^{\text {V8exp }}, 786-\mathrm{O}^{\text {VEGlexp }}, 786-\mathrm{O}^{\text {V7exp }}$ and $786-\mathrm{O}^{\text {v8exp }}$ cells as determined by western blot analysis $(\mathrm{P}<0.01)$ (Fig. 5). The protein expression of $\beta$-catenin and Slug declined in the A $498^{\text {VEGIexp }}, A 498^{\text {V7exp }}, A 498^{\text {V8exp }}, 786-\mathrm{O}^{\text {VEGIexp }}, 786-\mathrm{O}^{\text {V7exp }}$ and 786- $\mathrm{O}^{\mathrm{v8exp}}$ cells compared with these levels in the corresponding controls $(\mathrm{P}<0.01)$ (Fig. 6). However, differences in the effect of VEGI174, V7 and V8 overexpression on EMT markers in A498 or 786-O cells were not significant $(\mathrm{P}>0.05)$.

\section{Discussion}

VEGI, an endogenous inhibitor of endothelial cell proliferation, was first identified in human umbilical vein endothelial cells. VEGI is widely expressed in endothelial cells. Many studies have investigated the roles of VEGI in human cancers. This inhibitor is a promising candidate for cancer therapy. Parr et al (13) reported that VEGI is aberrantly expressed in breast cancer and displays prognostic relevance. Patients with breast tumours expressing reduced levels of VEGI had a poorer prognosis than those patients expressing high levels of VEGI. Chew et al (8) reported that overexpression of a secretable VEGI fusion protein abrogated xenograft tumour progression by reducing the tumour growth rate and microvessel density. VEGI also inhibited the growth of other human tumour cell lines, for instance, breast carcinoma (MCF-7), epithelial (HeLa) and myeloid (U-937 and ML-1a) tumour cells $(22,23)$. Our previous studies showed that overexpression of VEGI inhibited cell motility in vitro and vascular endothelial tube formation and tumour growth in vivo (14-16).

The EMT process is linked to its role in tumour invasion and metastasis. EMT has been established in multiple cancer types, such as digestive tract, pancreas, liver, prostate and breast cancers (24-30). Zhang et al (31) demonstrated that hypoxia was able to induce EMT and enhance the invasion 

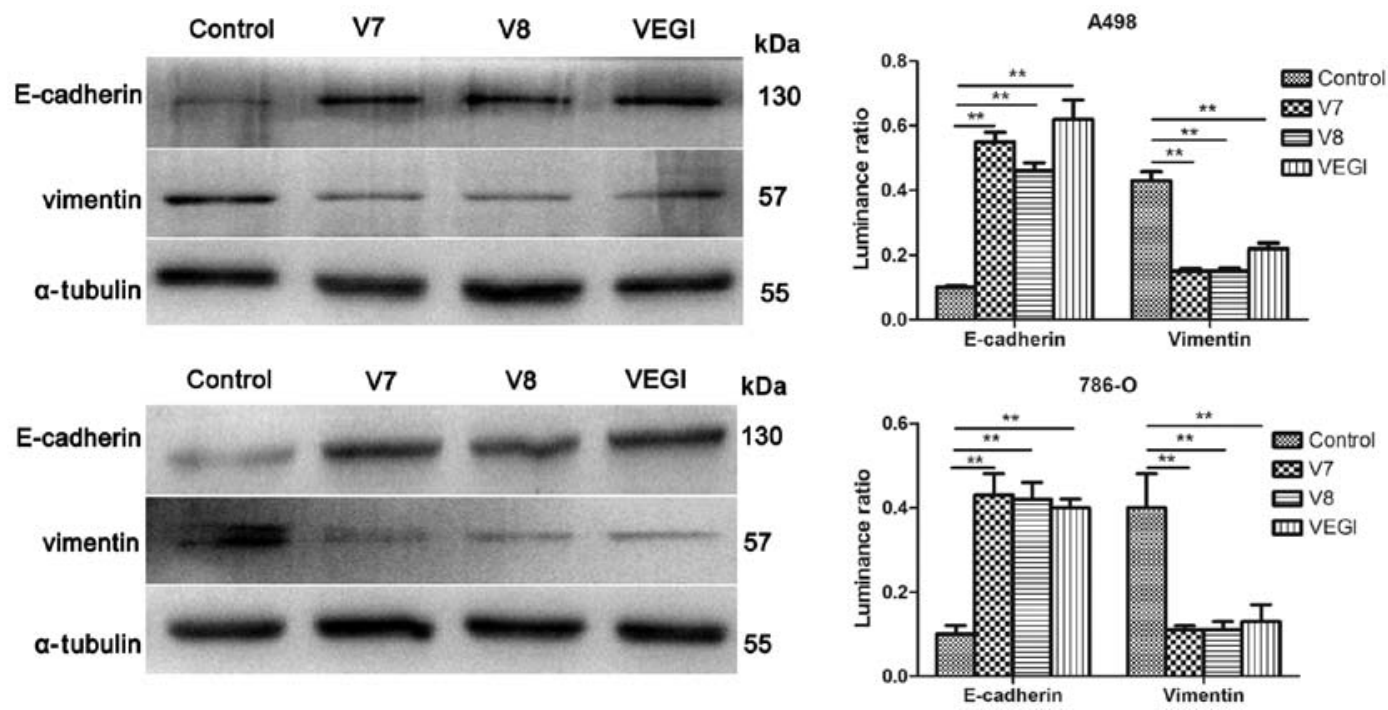

Figure 5. Western blotting showed that the protein expression of E-cadherin was increased and that of vimentin was reduced in the A498 ${ }^{\text {vEGlexp }}$, A498 $8^{\text {V7exp }}$, $\mathrm{A} 498^{\text {V8exp }}, 786-\mathrm{O}^{\text {VEGlexp }}, 786-\mathrm{O}^{\text {V7exp }}$ and 786- $\mathrm{O}^{\text {v8exp }}$ cells when compared with the empty plasmid controls $(\mathrm{P}<0.01)$. There were no significant differences in the expression of E-cadherin and vimentin between the A498 and 786-O cell lines that overexpressed vascular endothelial growth inhibitor 174 (VEGI174), V7 or V8 $(\mathrm{P}>0.05)$.
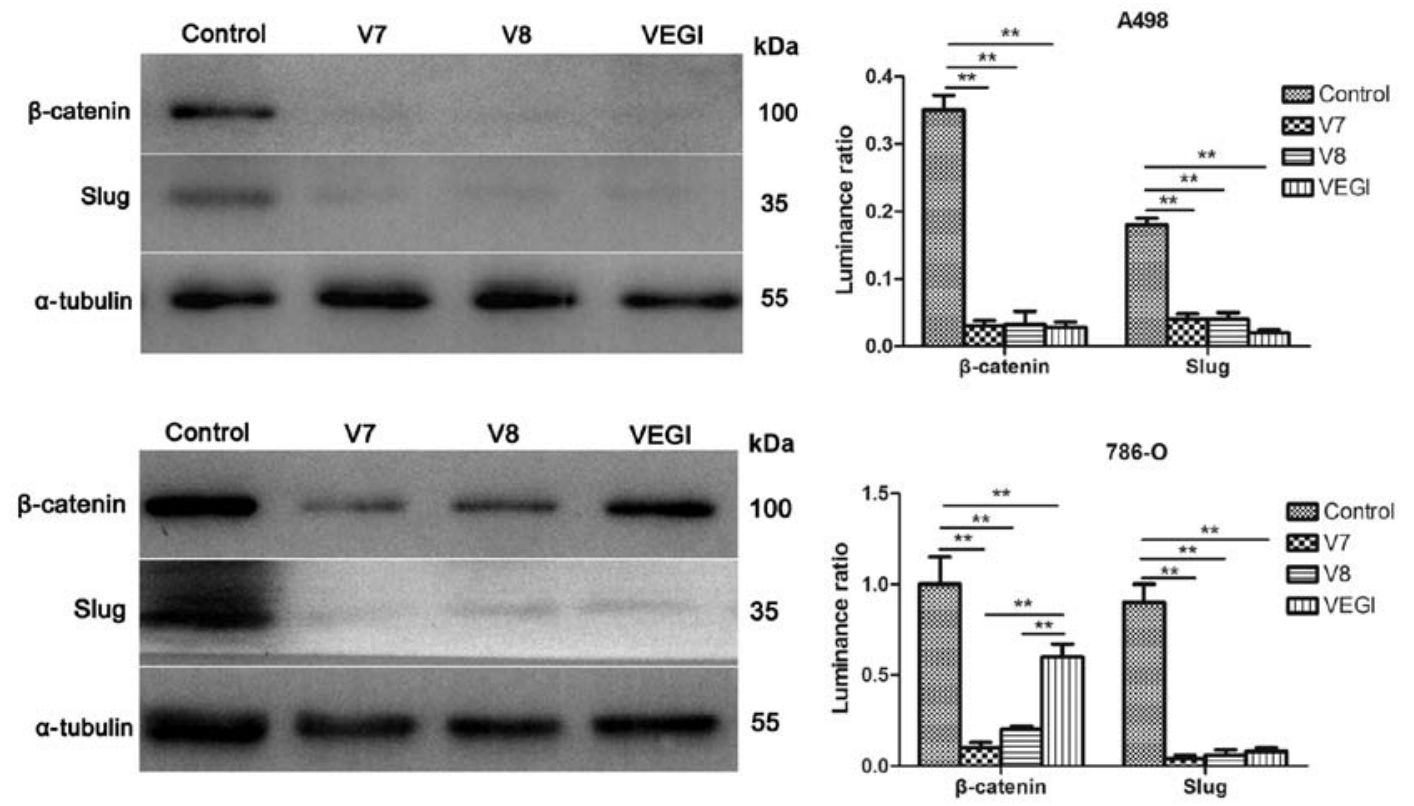

Figure 6. Western blotting showed that the protein expression of $\beta$-catenin and Slug declined in the A498 ${ }^{\text {VEGlexp }}, \mathrm{A} 498^{\text {V7exp }}, \mathrm{A}_{49} 8^{\text {V8exp }}, 786-\mathrm{O}^{\text {VEGlexp }}, 786-\mathrm{O}^{\text {V7exp }}$ and 786- $\mathrm{O}^{\mathrm{V8exp}}$ cells when compared with the empty plasmid controls $(\mathrm{P}<0.01)$. The expression of $\beta$-catenin was higher in the $786-\mathrm{O}^{\mathrm{VEGlexp}}$ cells than that noted in the 786-O $\mathrm{O}^{\text {v7exp }}$ and $786-\mathrm{O}^{\text {v8exp }}$ cells $(\mathrm{P}<0.01)$.

and migration ability of HCC cells. Chu et al (32) showed that EMT was closely related to in vitro cell migration and invasion in breast cancer. Therefore, further studies are needed to investigate the relationships between EMT development and cancer. These studies will offer insights into the oncogenic EMT pathways of tumour metastasis and provide potential therapeutic targets. Currently, the relationship between VEGI and EMT is not clear. In this study, we studied the effects of VEGI174 and its functional domains (V7 and V8) on EMT in RCC cells in vitro.

Our results confirmed that overexpression of VEGI174, V7 or V8 inhibited EMT in A498 and 786-O cell lines. The
mRNA level of E-cadherin was significantly upregulated, while vimentin was downregulated in the $\mathrm{A} 498^{\text {vEGIexp, }}$ $\mathrm{A} 498^{\text {V7exp }}, \mathrm{A} 498^{\text {v8exp }}, 786-\mathrm{O}^{\text {VEGIexp }}, 786-\mathrm{O}^{\mathrm{V} 7 \mathrm{exp}}$ and $786-\mathrm{O}^{\text {v8exp }}$ cells compared with that noted in the empty plasmid controls $(\mathrm{P}<0.05)$. Elevated protein expression of E-cadherin and decreased expression of vimentin were also observed in these cells compared with the corresponding controls $(\mathrm{P}<0.01)$. Thus, changes in the level of protein expression were consistent with the changes in mRNA expression. E-cadherin belongs to a family of calcium-dependent transmembrane glycoproteins. This glycoprotein is an intercellular adhesion molecule that enhances connections between cells and maintains the stability 
of the cytoskeleton. Many signalling pathways promote EMT by suppressing the expression of E-cadherin $(33,34)$. Importantly, vimentin, the mesenchymal intermediate filament and a hallmark of EMT, is overexpressed in malignant epithelial cancers and correlates with a poor prognosis (35). Thus, vimentin provides a further link between EMT and malignancy. Abundant evidence indicates that vimentin regulates mesenchymal cell shape and mammary epithelial cell migration and that it plays a role in regulating signal transduction, which is necessary for EMT induction (36-38).

Moreover, we also detected the expression of EMT-related regulatory factors ( $\beta$-catenin and Slug). $\beta$-catenin is a key mediator in the $\mathrm{Wnt} / \beta$-catenin signalling pathway. $\beta$-catenin translocates into the cell nucleus and promotes downstream pathways by binding to target genes $(39,40)$. Studies have shown that $\mathrm{Wnt} / \beta$-catenin signalling is associated with EMT (41-43). Slug, a member of the Snail family, is known to play diverse roles in the cell. Slug a transcriptional repressor, and its deregulation has been observed in a variety of cancers. Slug-mediated regulation of EMT is often associated with its ability to transcriptionally repress the expression of E-cadherin (44-47), and it has been shown to promote cancer cell invasion, migration and metastasis. In this study, compared with empty plasmid controls, $\beta$-catenin and Slug mRNA and protein expression levels were downregulated in the A498 and 786-O cells that overexpressed VEGI174, V7 or V8. These two proteins may be key regulatory factors in the mechanisms involved in suppression of the EMT process by VEGI174, V7 or V8 overexpression.

In conclusion, the present study showed that overexpression of VEGI174, V7 or V8 was able to inhibit the EMT process in the A498 and 786-O cell lines. This finding indicates that VEGI may be a potential tumour suppressor and target for RCC therapy. Furthermore, V7 and V8 are two effective functional domains of VEGI174, which can be considered for synthesis as peptides and further studied for the treatment of RCC.

\section{Acknowledgements}

This study was supported by the 2014 Beijing Natural Science Foundation (grant no. 7142059).

\section{References}

1. Siegel RL, Miller KD and Jemal A: Cancer statistics, 2016. CA Cancer J Clin 66: 7-30, 2016.

2. Liu L, Zhang W, Qi X, Li H, Yu J, Wei S, Hao X and Ren X: Randomized study of autologous cytokine-induced killer cell immunotherapy in metastatic renal carcinoma. Clin Cancer Res 18: 1751-1759, 2012.

3. Bianconi M, Faloppi L, Loretelli C, Zizzi A, Giampieri R, Bittoni A, Andrikou K, Del Prete M, Burattini L, Montironi R, et al: Angiogenesis genotyping in the selection of first-line treatment with either sunitinib or pazopanib for advanced renal cell carcinoma. Oncotarget 7: 37599-37607, 2016.

4. Buchler T, Bortlicek Z, Poprach A, Pavlik T, Veskrnova V, Honzirkova M, Zemanova M, Fiala O, Kubackova K, Slaby O, et al: Outcomes for patients with metastatic renal cell carcinoma achieving a complete response on targeted therapy: A Registry-based Analysis. Eur Urol 70: 469-475, 2015.

5. Fishman MN, Tomshine J, Fulp WJ and Foreman PK: A systematic review of the efficacy and safety experience reported for sorafenib in advanced renal cell carcinoma (RCC) in the postapproval setting. PLoS One 10: e0120877, 2015.
6. Tan KB, Harrop J, Reddy M, Young P, Terrett J, Emery J, Moore G and Truneh A: Characterization of a novel TNF-like ligand and recently described TNF ligand and TNF receptor superfamily genes and their constitutive and inducible expression in hematopoietic and non-hematopoietic cells. Gene 204: 35-46, 1997.

7. Zhai Y, Yu J, Iruela-Arispe L, Huang WQ, Wang Z, Hayes AJ, Lu J, Jiang G, Rojas L, Lippman ME, et al: Inhibition of angiogenesis and breast cancer xenograft tumor growth by VEGI, a novel cytokine of the TNF superfamily. Int J Cancer 82: 131-136, 1999.

8. Chew LJ, Pan H, Yu J, Tian S, Huang WQ, Zhang JY, Pang S and Li LY: A novel secreted splice variant of vascular endothelial cell growth inhibitor. FASEB J 16: 742-744, 2002.

9. Zhang N, Sanders AJ, Ye L and Jiang WG: Vascular endothelial growth inhibitor in human cancer (Review). Int J Mol Med 24: $3-8,2009$.

10. Zhai Y, Ni J, Jiang GW, Lu J, Xing L, Lincoln C, Carter KC, Janat F, Kozak D, Xu S, et al: VEGI, a novel cytokine of the tumor necrosis factor family, is an angiogenesis inhibitor that suppresses the growth of colon carcinomas in vivo. FASEB J 13: 181-189, 1999.

11. Liang PH, Tian F, Lu Y, Duan B, Stolz DB and Li LY: Vascular endothelial growth inhibitor (VEGI; TNFSF15) inhibits bone marrow-derived endothelial progenitor cell incorporation into Lewis lung carcinoma tumors. Angiogenesis 14: 61-68, 2011.

12. Yamanegi K, Kawabe M, Futani H, Nishiura H, Yamada N, Kato-Kogoe N, Kishimoto H, Yoshiya S and Nakasho K: Sodium valproate, a histone deacetylase inhibitor, modulates the vascular endothelial growth inhibitor-mediated cell death in human osteosarcoma and vascular endothelial cells. Int J Oncol 46: 1994-2002, 2015.

13. Parr $\mathrm{C}$, Gan $\mathrm{CH}$, Watkins $\mathrm{G}$ and Jiang WG: Reduced vascular endothelial growth inhibitor (VEGI) expression is associated with poor prognosis in breast cancer patients. Angiogenesis 9: 73-81, 2006.

14. Zhang N, Sanders AJ, Ye L, Kynaston HG and Jiang WG: Vascular endothelial growth inhibitor, expression in human prostate cancer tissue and the impact on adhesion and migration of prostate cancer cells in vitro. Int J Oncol 35: 1473-1480, 2009.

15. Zhang N, Sanders AJ, Ye L, Kynaston HG and Jiang WG: Expression of vascular endothelial growth inhibitor (VEGI) in human urothelial cancer of the bladder and its effects on the adhesion and migration of bladder cancer cells in vitro. Anticancer Res 30: 87-95, 2010.

16. Zhang N, Wu P, Shayiremu D, Wu L, Shan H, Ye L, Zhao X, Cai J, Jiang WG, Gong K, et al: Suppression of renal cell carcinoma growth in vivo by forced expression of vascular endothelial growth inhibitor. Int J Oncol 42: 1664-1673, 2013.

17. De Craene B and Berx G: Regulatory networks defining EMT during cancer initiation and progression. Nat Rev Cancer 13: 97-110, 2013

18. Thiery JP, Acloque H, Huang RY and Nieto MA: Epithelialmesenchymal transitions in development and disease. Cell 139: 871-890, 2009.

19. Wong IY, Javaid S, Wong EA, Perk S, Haber DA, Toner M and Irimia D: Collective and individual migration following the epithelial-mesenchymal transition. Nat Mater 13: 1063-1071, 2014.

20. Saad S, Stanners SR, Yong R, Tang O and Pollock CA: Notch mediated epithelial to mesenchymal transformation is associated with increased expression of the Snail transcription factor. Int $\mathbf{J}$ Biochem Cell Biol 42: 1115-1122, 2010.

21. Piva F, Giulietti M, Santoni M, Occhipinti G, Scarpelli M, Lopez-Beltran A, Cheng L, Principato G and Montironi R: Epithelial to mesenchymal transition in renal cell carcinoma: Implications for cancer therapy. Mol Diagn Ther 20: 111-117, 2016.

22. Xiao Q,Hsu CY,Chen H, Ma X,Xu J and Lee JM: Characterization of cis-regulatory elements of the vascular endothelial growth inhibitor gene promoter. Biochem J 388: 913-920, 2005.

23. Haridas V, Shrivastava A, Su J, Yu GL, Ni J, Liu D, Chen SF, Ni Y, Ruben SM, Gentz R, et al: VEGI, a new member of the TNF family activates nuclear factor-kappa B and c-Jun N-terminal kinase and modulates cell growth. Oncogene 18: 6496-6504, 1999.

24. Ho QT and Kuo CJ: Vascular endothelial growth factor: Biology and therapeutic applications. Int J Biochem Cell Biol 39: 1349-1357, 2007.

25. Byles V, Zhu L, Lovaas JD, Chmilewski LK, Wang J, Faller DV and Dai Y: SIRT1 induces EMT by cooperating with EMT transcription factors and enhances prostate cancer cell migration and metastasis. Oncogene 31: 4619-4629, 2012. 
26. Chen J, Imanaka N, Chen J and Griffin JD: Hypoxia potentiates Notch signaling in breast cancer leading to decreased E-cadherin expression and increased cell migration and invasion. $\mathrm{Br} \mathrm{J}$ Cancer 102: 351-360, 2010

27. Sato F, Kubota Y, Natsuizaka M, Maehara O, Hatanaka Y, Marukawa K, Terashita K, Suda G, Ohnishi S, Shimizu Y, et al: EGFR inhibitors prevent induction of cancer stem-like cells in esophageal squamous cell carcinoma by suppressing epithelialmesenchymal transition. Cancer Biol Ther 16: 933-940, 2015

28. Jiao L, Li DD, Yang CL, Peng RQ, Guo YQ, Zhang XS and Zhu XF: Reactive oxygen species mediate oxaliplatin-induced epithelial-mesenchymal transition and invasive potential in colon cancer. Tumour Biol 37: 8413-8423, 2016.

29. Liang B, Zheng W, Fang L, Wu L, Zhou F, Yin X, Yu X and Zou Z: Overexpressed targeting protein for Xklp2 (TPX2) serves as a promising prognostic marker and therapeutic target for gastric cancer. Cancer Biol Ther 17: 824-832, 2016.

30. Krantz SB, Shields MA, Dangi-Garimella S, Munshi HG and Bentrem DJ: Contribution of epithelial-to-mesenchymal transition and cancer stem cells to pancreatic cancer progression. J Surg Res 173: 105-112, 2012.

31. Zhang L, Huang G, Li X, Zhang Y, Jiang Y, Shen J, Liu J, Wang Q, Zhu J, Feng X, et al: Hypoxia induces epithelial-mesenchymal transition via activation of SNAI1 by hypoxia-inducible factor-1 $\alpha$ in hepatocellular carcinoma. BMC Cancer 13: 108, 2013.

32. Chu CY, Jin YT, Zhang W, Yu J, Yang HP, Wang HY, Zhang ZJ, Liu XP and Zou Q: CA IX is upregulated in $\mathrm{CoCl}_{2}$-induced hypoxia and associated with cell invasive potential and a poor prognosis of breast cancer. Int J Oncol 48: 271-280, 2016.

33. Lombaerts $M$, van Wezel T, Philippo K, Dierssen JW Zimmerman RM, Oosting J, van Eijk R, Eilers PH, van de Water B, Cornelisse CJ, et al: E-cadherin transcriptional downregulation by promoter methylation but not mutation is related to epithelialto-mesenchymal transition in breast cancer cell lines. Br J Cancer 94: 661-671, 2006.

34. Natalwala A, Spychal R and Tselepis C: Epithelial-mesenchymal transition mediated tumourigenesis in the gastrointestinal tract. World J Gastroenterol 14: 3792-3797, 2008.

35. Satelli A and Li S: Vimentin in cancer and its potential as a molecular target for cancer therapy. Cell Mol Life Sci 68: 3033-3046, 2011

36. Gilles C, Polette M, Zahm JM, Tournier JM, Volders L, Foidart JM and Birembaut P: Vimentin contributes to human mammary epithelial cell migration. J Cell Sci 112: 4615-4625, 1999.
37. Mendez MG, Kojima S and Goldman RD: Vimentin induces changes in cell shape, motility, and adhesion during the epithelial to mesenchymal transition. FASEB J 24: 1838-1851, 2010.

38. Vuoriluoto K, Haugen H, Kiviluoto S, Mpindi JP, Nevo J, Gjerdrum C, Tiron C, Lorens JB and Ivaska J: Vimentin regulates EMT induction by Slug and oncogenic $\mathrm{H}$-Ras and migration by governing Axl expression in breast cancer. Oncogene 30: 1436-1448, 2011

39. Polakis P: Wnt signaling and cancer. Genes Dev 14: 1837-1851, 2000.

40. Giles RH, van Es JH and Clevers H: Caught up in a Wnt storm: Wnt signaling in cancer. Biochim Biophys Acta 1653: 1-24, 2003.

41. Kwon YJ, Baek HS, Ye DJ, Shin S, Kim D and Chun YJ: CYP1B1 enhances cell proliferation and metastasis through induction of EMT and activation of Wnt/ $\beta$-catenin signaling via Sp1 upregulation. PLoS One 11: e0151598, 2016.

42. Lee SC, Kim OH, Lee SK and Kim SJ: IWR-1 inhibits epithelialmesenchymal transition of colorectal cancer cells through suppressing Wnt/ $\beta$-catenin signaling as well as survivin expression. Oncotarget 6: 27146-27159, 2015.

43. Ai R, Sun Y, Guo Z, Wei W, Zhou L, Liu F, Hendricks DT, Xu Y, Zhao X: NDRG1 overexpression promotes the progression of esophageal squamous cell carcinoma through modulating Wnt signaling pathway. Cancer Biol Ther 17: 943-954, 2016.

44. Bolós V, Peinado H, Pérez-Moreno MA, Fraga MF, Esteller M and Cano A: The transcription factor Slug represses E-cadherin expression and induces epithelial to mesenchymal transitions: A comparison with Snail and E47 repressors. J Cell Sci 116: 499-511, 2003.

45. Storci G, Sansone P, Trere D, Tavolari S, Taffurelli M, Ceccarelli C, Guarnieri T, Paterini P, Pariali M, Montanaro L, et al: The basallike breast carcinoma phenotype is regulated by SLUG gene expression. J Pathol 214: 25-37, 2008.

46. Hajra KM, Chen DY and Fearon ER: The SLUG zinc-finger protein represses E-cadherin in breast cancer. Cancer Res 62 : 1613-1618, 2002.

47. Martin TA, Goyal A, Watkins G and Jiang WG: Expression of the transcription factors snail, slug, and twist and their clinical significance in human breast cancer. Ann Surg Oncol 12: 488-496, 2005 